\title{
Constitutive Analysis on High-Temperature Flow Behavior of 3Cr-1Si-1Ni Ultra-High Strength Steel for Modeling of Flow Stress
}

\author{
Bingwang Lei ${ }^{1,2}$, Gaoqiang Chen ${ }^{1}$, Kehong Liu ${ }^{2}$, Xin Wang ${ }^{1}$, Xiaomei Jiang ${ }^{2}$, Jiluan Pan ${ }^{1}$ and \\ Qingyu Shi ${ }^{1, *}$ \\ 1 Department of Mechanical Engineering, Tsinghua University, Beijing 100084, China; \\ leibingwang@163.com (B.L.); cheng1@tsinghua.edu.cn (G.C.); zq05@sohu.com (X.W.); \\ pjl-dme@tsinghua.edu.cn (J.P.) \\ 2 Inner Mongolia North Heavy Industries Group Corp., Ltd., Baotou, Inner Mongolia 014033, China; \\ 13847203575@163.com (K.L.); 360jxm@163.com (X.J.) \\ * Correspondence: shqy@tsinghua.edu.cn; Tel.: +86-6277-3796
}

Received: 26 November 2018; Accepted: 29 December 2018; Published: 5 January 2019

\begin{abstract}
High-temperature plastic flow is the underlying process that governs the product quality in many advanced metal manufacturing technologies, such as extrusion, rolling, and welding. Data and models on the high-temperature flow behavior are generally desired in the design of these manufacturing processes. In this paper, quantitative constitutive analysis is carried out on $3 \mathrm{Cr}-1 \mathrm{Si}-1 \mathrm{Ni}$ ultra-high strength steel, which sheds light on the mathematic relation between the flow stress and the thermal-mechanical state variables, such as temperature, plastic strain, and strain rate. Particularly, the hyperbolic-sine equation in combination with the Zener-Hollomon parameter is shown to be successful in representing the effect of temperature and strain rate on the flow stress of the $3 \mathrm{Cr}-1 \mathrm{Si}-1 \mathrm{Ni}$ steel. It is found that the flow stress of the $3 \mathrm{Cr}-1 \mathrm{Si}-1 \mathrm{Ni}$ steel is significantly influenced by strain. The strain-dependence on flow stress is not identical at different temperatures and strain rates. In the constitutive model, the influence of strain in the constitutive analysis is successfully implemented by introducing strain-dependent constants for the constitutive equations. Fifth-order polynomial equations are employed to fit the strain-dependence of the constitutive constant. The proposed constitutive equations which considers the compensation of strain is found to accurately predict flow stress of the $3 \mathrm{Cr}-1 \mathrm{Si}-1 \mathrm{Ni}$ steel at the temperatures ranging from $800{ }^{\circ} \mathrm{C}$ to $1250{ }^{\circ} \mathrm{C}$, strain rate ranging from $0.01 / \mathrm{s}$ to $10 / \mathrm{s}$, and strain ranging from 0.05 to 0.6 .
\end{abstract}

Keywords: ultra-high strength steel; hot deformation; constitutive model; plastic deformation; high-temperature flow behavior

\section{Introduction}

In the advanced metal manufacturing technologies, high-temperature plastic flow is widely utilized as the underlying physical processes for various purposes including rolling [1], extrusion [2], and welding [3]. Fundamental knowledge on the flow behavior of metal and its alloys at high temperatures is of critical importance in the understanding of the thermal-mechanical processing condition during the high-temperature plastic flow, in order to support the design and optimization of the metal processing technologies. Generally, constitutive analysis of the flow behaviors, which sheds quantitative light on the relation between the flow stress and the thermal-mechanical state variables, such as temperature, plastic strain, and strain rate, is desired as the knowledge basis for development and investigation of processing technology of advanced metals/alloys. This is also the case for ultra-high strength steels. $3 \mathrm{Cr}-1 \mathrm{Si}-1 \mathrm{Ni}$ is a newly developed medium alloyed ultra-high strength 
steel. In order to obtain high strength and toughness, the elements such as Cr, Ni, Mo, Mo, Si, W, V, $\mathrm{Nb}$, and others are used, while Co is avoided to reduce cost. The existence of these alloy elements and their carbides lead to significantly enhanced mechanical toughness. On the other hand, the fact that the carbides may retain at elevated temperatures make the high temperature flow behavior of $3 \mathrm{Cr}-1 \mathrm{Si}-1 \mathrm{Ni}$ a very complex problem. In these regards, the comprehensive constitutive analysis on the flow behaviors of the $3 \mathrm{Cr}-1 \mathrm{Si}-1 \mathrm{Ni}$ ultra-high strength steel is greatly required to clarify its flow behaviors at high temperatures.

In the previous studies, efforts have been paid to the constitutive analysis for different metals and alloys, especially the constitutive equations for accurately predict the flow stress at different thermal-mechanical conditions. Sellars and McTegart [4] proposed a constitutive equation for hot deformation, in which the Arrhenius equation is combined with a hyperbolic-sine equation in describing the non-linear relation between the flow stress, temperature, and strain rate. This constitutive equation has long been employed for modeling different metals [5,6], which was comprehensively reviewed by McQueen and Ryan [7]. The equations have proven to be able to model the flow stress in different deformation stages, such as the peak stress and the steady state stress. It has been shown to be important to include the influence of strain in the constitutive model, especially when the model is applied in the analysis of the complex material processing [8]. Sloof et al. [9] proposed the concept of introducing a strain-dependent parameter in modeling the flow stress of Mg-Al4-Zn1 alloy to include the influence of the strain on the flow stress at high temperatures. In more recent studies, Lin et al. [10] proposed a modified constitutive equation hyperbolic-sine, in which the activation energy and constitutive constants are conducted as a function of strain. In more recent studies, the modified constitutive equation by Lin et al. [10] has been demonstrated to be successful in modeling the high-temperature flow behavior of different metallic materials, such as steels [11-13], magnesium alloys [14-16], aluminum alloy [8,17,18], titanium alloy [19,20], copper alloy [21], and metal matrix composite [22,23]. We note that most of the published works are phenomenological or empirical in considering the influence of strain on the flow stresses. It is also worth noting that the continuous research interests has brought out new physical based constitutive models in the very recent studies [24,25]. However, to the best of our knowledge, very limited investigation has been reported on the ultra-high strength steel. More investigation is needed to conduct constitutive analysis on the ultra-high strength steel in order to advance the understanding of the high temperature flow behaviors of different types of metals/alloys.

In this paper, we aim to conduct the constitutive analysis on the recently developed $3 \mathrm{Cr}-1 \mathrm{Si}-1 \mathrm{Ni}$ ultra-high strength steel. The relation between the flow stress and the thermal-mechanical factors is quantified. First, a series of hot compression tests were carried out to cover wide material flow conditions, in which the flow stress, temperature, strain, and strain rate are measured and recorded. Second, the approaches regarding experiments and the analysis of the experimental measured data is described in order to determine the constants in the constitute models, while the compensation of strain is considered. Third, the validity of the obtained constitutive model has been discussed.

\section{Approaches}

\subsection{Experiments}

The uniaxial hot compression experiment is carried out by using the Thermal-Mechanical Simulators Gleeble-3500 by Dynamic Systems Inc. (Austin, TX, USA). Cylindrical specimens of $\Phi 10 \mathrm{~mm} \times 15 \mathrm{~mm}$ were cut from a forged billet. Similar specimen size was used in the published work $[10,11]$. The chemical composition of the $3 \mathrm{Cr}-1 \mathrm{Si}-1 \mathrm{Ni}$ ultra-high strength steel is shown in Table 1. The specimens were clamped individually between the two dies. For each specimen, the deformation temperature and strain rate were constant, and the flow stress is recorded as function of strain. A total of 50 specimens were used for the experiments at different temperature and strain rate. The testing temperatures were design to range from $800{ }^{\circ} \mathrm{C}$ to $1250{ }^{\circ} \mathrm{C}$ with an interval of $50{ }^{\circ} \mathrm{C}$. In the tests, 
the temperature of the sample was programed as function of time. The temperature curve is illustrated in Figure 1. There were two modes in the heating and cooling process in the tests. For the tests in the temperature from $800{ }^{\circ} \mathrm{C}$ to $1150{ }^{\circ} \mathrm{C}$, mode-I was used where the specimen was pre-heated up to $1150{ }^{\circ} \mathrm{C}$ at the rate of $10^{\circ} \mathrm{C} / \mathrm{s}$, after which a hold time at $1150{ }^{\circ} \mathrm{C}$ of $180 \mathrm{~s}$ was employed. Thereafter, the specimens were cooled down at $10{ }^{\circ} \mathrm{C} / \mathrm{s}$ to the testing temperature. After a short dwelling for $30 \mathrm{~s}$, the hot compression test was carried out. Mode-II was used for the tests with temperatures from $1150{ }^{\circ} \mathrm{C}$ to $1250{ }^{\circ} \mathrm{C}$, the specimen was heated up at $10^{\circ} \mathrm{C} / \mathrm{s}$ to the testing temperature directly. Before the compression tests, a hold time of $180 \mathrm{~s}$ was used. The strain rate was taken as $0.01 / \mathrm{s}$, $0.1 / \mathrm{s}, 1 / \mathrm{s}, 5 / \mathrm{s}$, and $10 / \mathrm{s}$, respectively. After the tests, the specimen was quenched with water to room temperature.

Table 1. Chemical Composition of 3Cr-1Si-1Ni Steel (Mass Fraction, \%).

\begin{tabular}{cccccccccc}
\hline $\mathbf{C}$ & $\mathbf{M n}$ & $\mathbf{S i}$ & $\mathbf{S}$ & $\mathbf{P}$ & $\mathbf{C r}$ & $\mathbf{N i}$ & $\mathbf{M o}$ & $\mathbf{N b}$ & $\mathbf{W}$ \\
\hline 0.30 & 0.66 & 1.47 & 0.001 & 0.010 & 3.48 & 1.06 & 0.44 & 0.02 & 0.84 \\
\hline
\end{tabular}

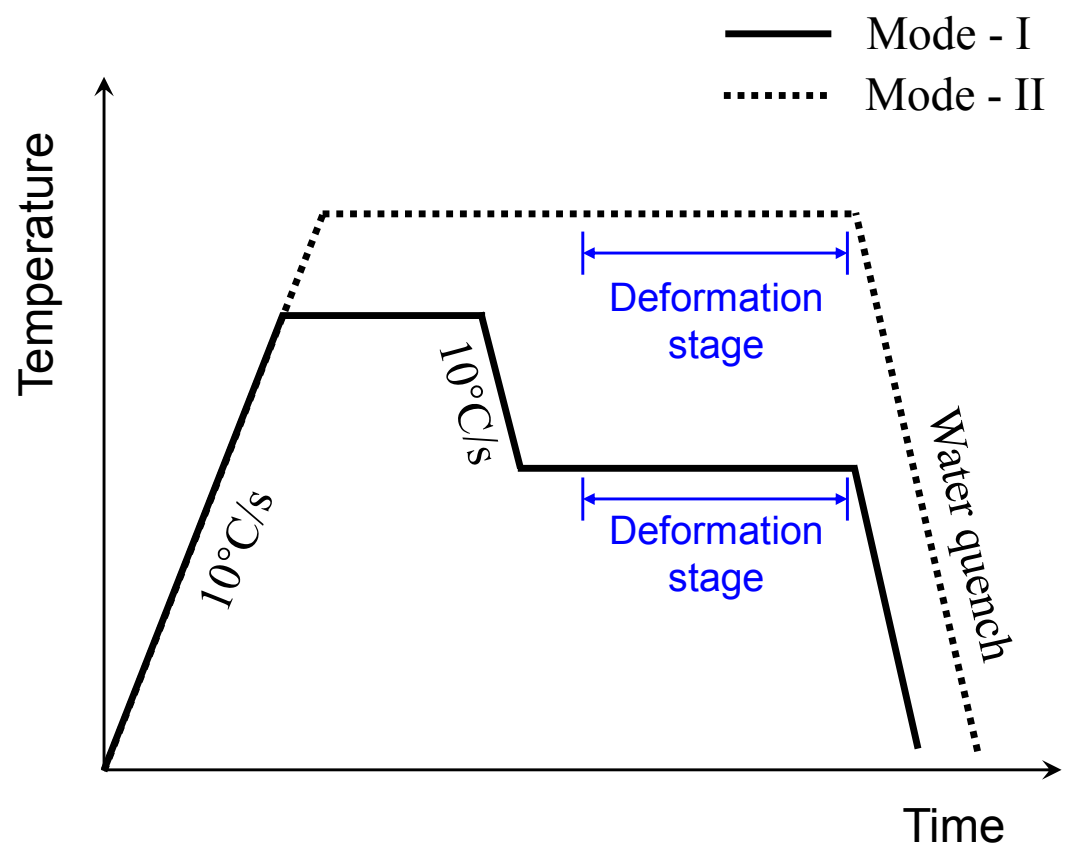

Figure 1. Illustration of the heating and cooling process in the hot compression tests.

\subsection{Constitutive Model and Approaches to Determine the Constitutive Constants}

In the constitutive model, the analytical equations are used to relate the flow stress to the thermal mechanical state variables. In our analysis, we consider all the thermal-mechanical state variables in the experiment, which are temperature, strain and strain rate. The Zener-Hollomon parameter is used to reflect the effect of temperature and strain rate which is given as [26]:

$$
Z=\dot{\varepsilon} \exp (Q / R T)
$$

The hyperbolic-sine function [4] is employed to consider the effects of temperature and strain rate on the flow stress in the constitutive analysis on the high temperature flow behavior of $3 \mathrm{Cr}-1 \mathrm{Si}-1 \mathrm{Ni}$ ultra-high strength steel. The expression is shown as follows:

$$
\dot{\varepsilon} \exp (Q / R T)=A[\sinh (\alpha \sigma)]^{n}
$$


where $\dot{\varepsilon}$ is strain rate, $\sigma$ is flow stress, $Q$ is deformation activation energy $(\mathrm{J} / \mathrm{mol}), R$ is gas constant $(8.314 \mathrm{~J} / \mathrm{mol} / \mathrm{K}), T$ is temperature in $\mathrm{K}$ and $\alpha, A$, and $n$ are adjustable constitutive constants. Equation (2) has proven to be able to model the flow stress in different deformation stages corresponding to different strain levels [7], such as the peak stress and steady state stress. Therefore, we use Equation (2) to model the relation between the flow stress, temperature, and strain rate at different strain levels. There are, in total, four constants which are needed to be determined in Equation (2), which are $Q, \alpha, A$, and $n$. All these constitutive constants in Equation (2) are determined by using fitting processes. In order to fit the constants, we take logarithm of Equation (2) at both sides and have:

$$
\ln \dot{\varepsilon}+Q / R T=\ln A+n \ln [\sinh (\alpha \sigma)]
$$

Multiple steps of data processing are utilized to determine the constitutive constants. The process steps are described below.

Step 1. Determination of $\alpha$. The constant $\alpha$ is a scale factor for the flow stress $\sigma$. The value of $\alpha$ has certain range for steels. Typical values of $\alpha$ for steels in the references [11-13] are taken as the initial range for determination of in this paper. The range is selected to be [0.001, 0.100]. A direct search approach is used to determine the proper value of $\alpha$. For a specified value of $\alpha$, we use Step 2 to Step 4 to calculate the parameters of $n, Q$ and $A$. Thereafter, the residual is calculated to evaluate the quality of fitting process. The value of $\alpha$ is then determined when the residual reaches its minimal.

Step 2. Determination of $n$. The equation below is obtained from Equation (3):

$$
n=\left.\frac{\partial(\ln \dot{\varepsilon})}{\partial\{\ln [\sinh (\alpha \sigma)]\}}\right|_{T}
$$

By using the flow stress $\sigma$ and strain rate $\varepsilon$ at each test with the same temperature, the values of $n$ are determined. By taking average of these values, the value of $n$ is determined.

Step 3. Determination of $Q$. The thermal activation energy, $Q$, depicts the variation of flow stress versus temperature. The equation below derived from Equation (3) is employed to get the value of $Q$ by using linear fitting process, which is given as:

$$
Q=\left.R n\left[\frac{\partial\{\ln [\sinh (\alpha \sigma)]\}}{\partial(1 / T)}\right]\right|_{\dot{\varepsilon}}
$$

By using the flow stress $\sigma$ and temperature $T$ (in K) at each test with identical strain rate, the values of $Q$ is determined. By averaging of these values for different strain rates, the value of $Q$ is determined.

Step 4. Determination of $A$. In order to determine the value of $A$ by using a linear fitting process, we use the equation below to calculate $A$ :

$$
A=\left.\frac{\partial Z}{\partial[\sinh (\alpha \sigma)]^{n}}\right|_{T}=\left.\frac{\partial[\dot{\varepsilon} \exp (Q / R T)]}{\partial[\sinh (\alpha \sigma)]^{n}}\right|_{T}
$$

By using the Zener-Hollomon parameter $Z$ and flow stress $\sigma$ at each test with constant temperature, the values of $\ln A$ could be determined. By averaging these values for different temperatures, the final value of $A$ is determined. Microsoft Excel was used to calculate the slope by the linear fitting process. A direct search approach is implemented by using the embedded programing tool, Visual Basic for Applications in Microsoft Excel.

\section{Results and Discussion}

\subsection{Measured Flow Stress}

Figure 2 shows the measured flow stress curve of 3Cr-1Si-1Ni ultra-high strength steel at different deformation temperatures and strain rates in the experiments. In the figure, the experiment data at different deformation temperatures is grouped by the value of strain rate. It could be seen from 
Figure $2 \mathrm{a}-\mathrm{e}$ that the flow stress decreases with the increase of deformation temperature at constant strain rate, while the flow stress has a trend to increase with the increase of strain rate. Additionally, the flow stress is also significantly dependent on the strain. For each specimen which is tested at constant temperature and constant strain rate, the flow stress rapidly increases at the beginning of the compression until it reaches $\sim 0.2$, which is termed as strain hardening. The hardening is generally caused by the accumulation of crystal defects, such as dislocations. When the strain exceeds the value of $\sim 0.2$, the flow stress curve become relatively flat because of the softening induced by dynamic recovery and dynamic recrystallization. It is worth noting that the strain dependency of flow stress is found to be varying with testing conditions. For example, the measured flow stress at $1050{ }^{\circ} \mathrm{C}$ exhibits both strain hardening and strain softening at strain rate of 0.01 /s (Figure 2a) and 0.1/s (Figure 2b), while continuous strain hardening is present at strain rate of 1.0/s (Figure 2c), 5.0/s (Figure 2d), and 10.0/s (Figure 2e). This might be caused by the competition between the generation of crystal defects and the softening regime. In the metal manufacturing processes, complex accumulation of strain occurs to materials during the processing [27-29]. In this regard, analysis on the dependency of flow stress on the strain is required in order to understand the flow behaviors of the material during the material processing. This motivates the further analysis of the strain-dependency of the constitutive constants.
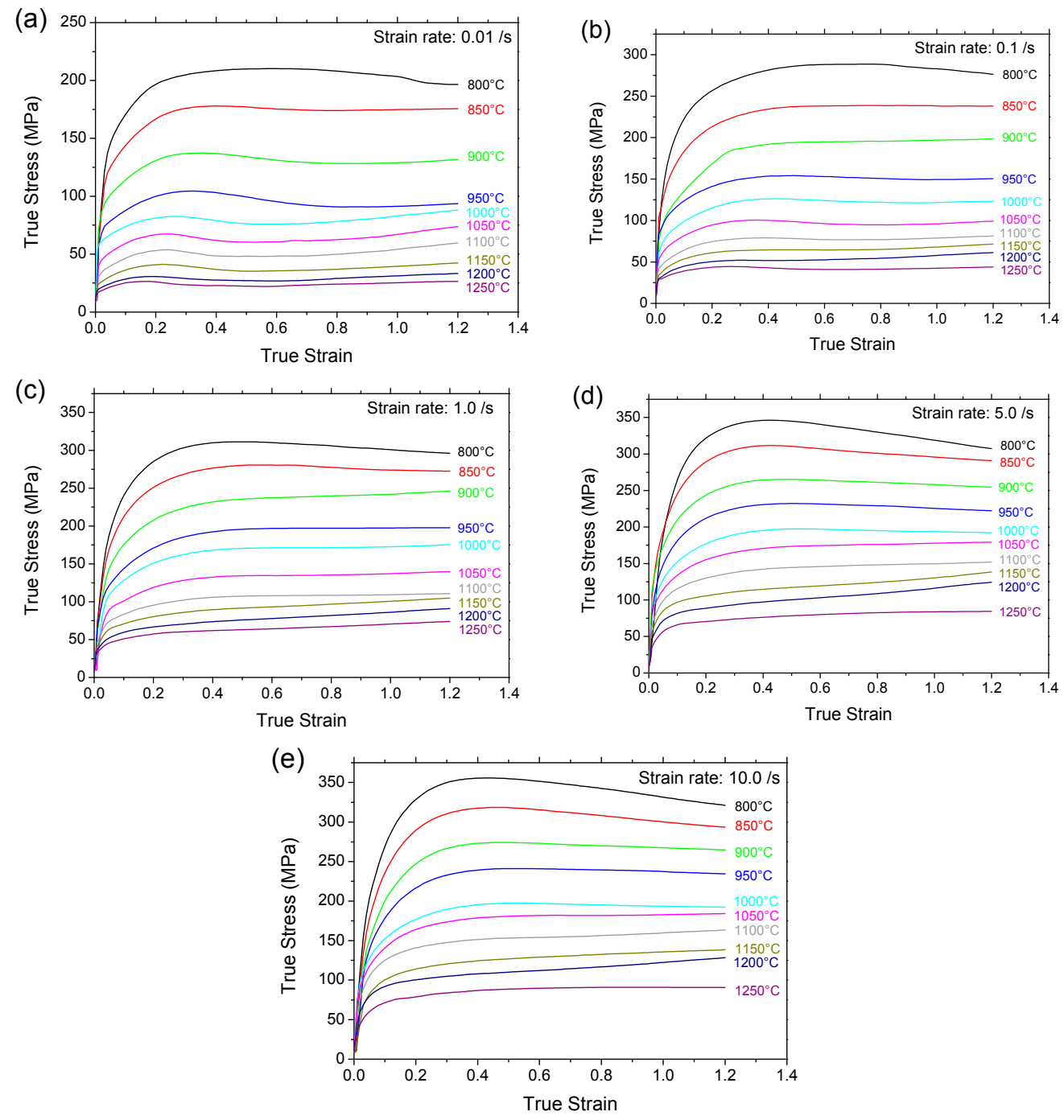

Figure 2. Measured flow stress of $3 \mathrm{Cr}-1 \mathrm{Si}-1 \mathrm{Ni}$ ultra-high strength steel. The experiment data at different deformation temperatures is grouped by $(\mathbf{a}) 0.01 / \mathrm{s},(\mathbf{b}) 0.1 / \mathrm{s}$, (c) $1.0 / \mathrm{s}$, (d) $5.0 / \mathrm{s}$, and (e) $10.0 / \mathrm{s}$. 


\subsection{Determination of Constitutive Constants}

It is known from Equation (3) that the flow stress at a particular strain could be considered as a function of temperature and strain rate. As an example, the flow stresses at the true strain of 0.3 with different temperatures and strain rates are used for calculation of the constants. By using the approach described in Section 2.2, the constitutive constants in Equation (3) are determined. The determined values are $\alpha=0.0086805, Q=431,237.6 \mathrm{~J} / \mathrm{mol}, n=5.50294$, and $\ln A=37.4838$. Figure 3 shows the comparison of the predicted and measured flow stresses in the plot of $\ln (\sinh (\alpha \sigma))$ versus $1 / T$ at different strain rates. It could be seen that the Equation (3) with the determined constants is successful in describing the flow stress values. It is clear that the slopes of the lines are almost equal, which indicates that the activation energy for plastic deformation is almost identical at different strain rates. As abovementioned, the thermal activation energy, $Q$, is determined as $431,237.6 \mathrm{~J} / \mathrm{mol}$. This is comparable, but slightly higher than the thermal-activation energy of other steels, which is $372 \mathrm{~kJ} / \mathrm{mol}$ for 9Cr-1Mo steel [30] and 387.84 kJ/mol for Fe-20Mn-3Si-3Al steel [31].

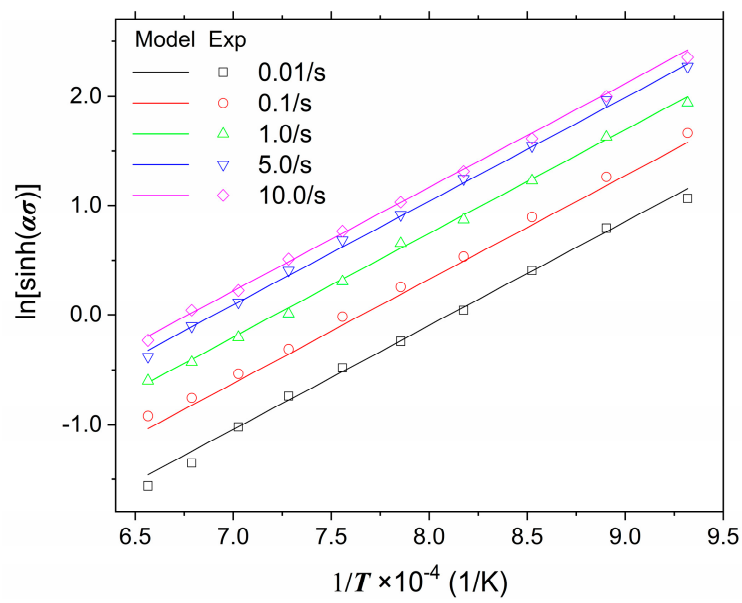

Figure 3. Comparison of the predicted and measured flow stresses in the plot of $\ln (\sinh (\alpha \sigma))$ versus $1 / T$ at different strain rate. The strain is 0.3 .

In the applications of the constitutive model such as the processing models [32-34], the flow stress is generally needed to be calculated by using the constitutive model. If all the constitutive constants are already determined, the flow stress at certain thermal-mechanical condition could be determined by the following equation, which is obtained by rearranging Equation (2):

$$
\sigma=\frac{1}{\alpha} \sinh ^{-1}\left[\left(\frac{\dot{\varepsilon}}{A} \exp \left(\frac{Q}{R T}\right)\right)^{\frac{1}{n}}\right]=\sigma_{R} \sinh ^{-1}\left[\left(\frac{\dot{\varepsilon}}{A} \exp \left(\frac{Q}{R T}\right)\right)^{\frac{1}{n}}\right]
$$

A parameter $\sigma_{R}$ is used to replace $\frac{1}{\alpha}$. In order to consider the compensation of strain, the constitutive constants for different strains are calculated by the above approach in Section 2.2. The fitted values of constitutive constants in different strains is shown in Figure 4 . These constitutive constants are fitted into fifth polynomial equations of the strain $\varepsilon$, which are expressed as the equations below. The coefficient of the polynomial equations are summarized in Table 2.

$$
\begin{gathered}
\sigma_{R}=\frac{1}{\alpha}=\sigma_{R 0}+\sigma_{R 2} \varepsilon+\sigma_{R 2} \varepsilon^{2}+\sigma_{R 3} \varepsilon^{3}+\sigma_{R 4} \varepsilon^{4}+\sigma_{R 5} \varepsilon^{5} \\
n=n_{0}+n_{1} \varepsilon+n_{2} \varepsilon^{2}+n_{3} \varepsilon^{3}+n_{4} \varepsilon^{4}+n_{5} \varepsilon^{5} \\
Q=Q_{0}+Q_{1} \varepsilon+Q_{2} \varepsilon^{2}+Q_{3} \varepsilon^{3}+Q_{4} \varepsilon^{4}+Q_{5} \varepsilon^{5} \\
\ln A=A_{0}+A_{1} \varepsilon+A_{2} \varepsilon^{2}+A_{3} \varepsilon^{3}+A_{4} \varepsilon^{4}+A_{5} \varepsilon^{5}
\end{gathered}
$$


(a)

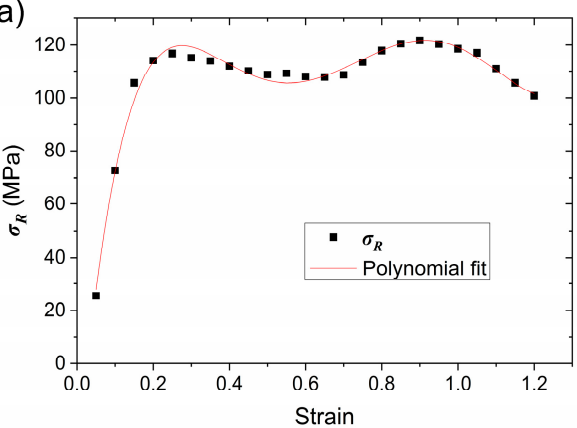

(c)

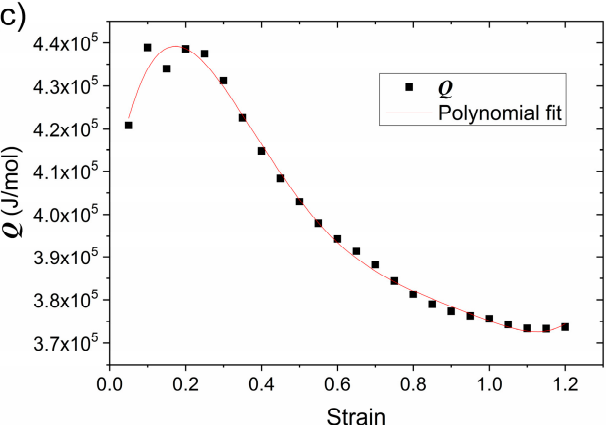

(b)

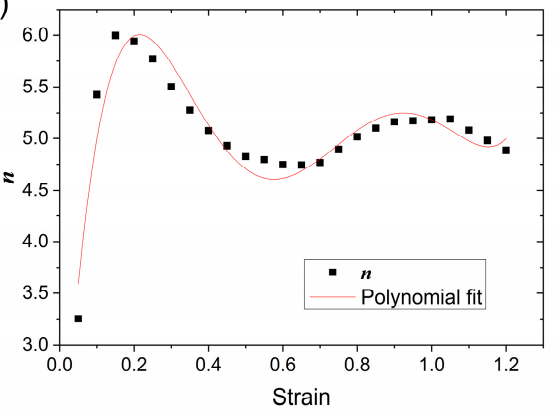

(d)

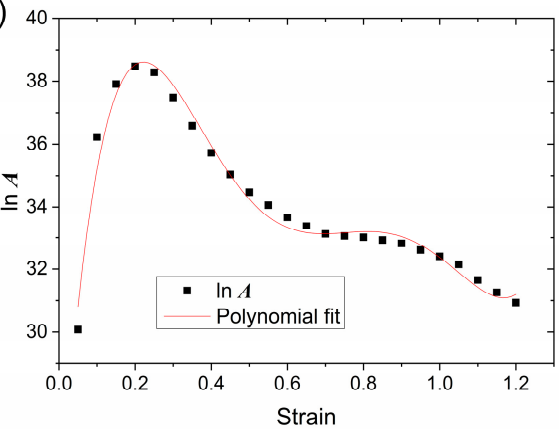

Figure 4. Constitutive constants at different strains. (a) $\sigma_{R},(\mathbf{b}) n,(\mathbf{c}) Q,(\mathbf{d}) \ln A$.

Table 2. Polynomial coefficients for the constitutive constants.

\begin{tabular}{cccc}
\hline$\sigma_{R}$ Coefficients & $n$ Coefficients & $Q$ Coefficients & $\ln A$ Coefficients \\
\hline$\sigma_{R 0}=-39.84493$ & $n_{0}=1.26676$ & $Q_{0}=402,186.36438$ & $A_{0}=23.71189$ \\
$\sigma_{R 1}=1629.75612$ & $n_{1}=57.48761$ & $Q_{1}=511,823.06999$ & $A_{1}=174.15151$ \\
$\sigma_{R 2}=-5979.42037$ & $n_{2}=-239.83975$ & $Q_{2}=-2.28104 \mathrm{E} 6$ & $A_{2}=-699.4766$ \\
$\sigma_{R 3}=9660.61798$ & $n_{3}=411.91514$ & $Q_{3}=3.66587 \mathrm{E} 6$ & $A_{3}=1158.47548$ \\
$\sigma_{R 4}=-7046.50103$ & $n_{4}=-312.9979$ & $Q_{4}=-2.64018 \mathrm{E} 6$ & $A_{4}=-862.84646$ \\
$\sigma_{R 5}=1894.5171$ & $n_{5}=87.35124$ & $Q_{5}=716,469.7527$ & $A_{5}=238.35241$ \\
\hline
\end{tabular}

\subsection{Verification of the Constitutive Equations}

The comparison of the flow stress between predicted by constitutive equations and measured by tests is presented in Figure 5. The prediction of flow stress at different thermal-mechanical conditions is performed by combining Equations (7)-(11). Figure 5a shows the comparison between the predicted and measured value of flow stress as a function of temperature at different level of strain rates when the strain is 0.6 . The proposed constitutive equations are found to be able to predict the flow stress very well. Figure $5 \mathrm{~b}$ shows the comparison between the predicted and measured values of the flow stress a function of strain at different strain rate at temperature of $1250^{\circ} \mathrm{C}$. It could be seen that the strain dependency of the flow stress could be captured by the proposed constitutive equations. Additionally, it is confirmed from Figure 6 that the constitutive Equations (7)-(11) in this paper are able to predict the flow stress at the temperatures ranging from $800{ }^{\circ} \mathrm{C}$ to $1250{ }^{\circ} \mathrm{C}$, strain rates ranging from $0.01 / \mathrm{s}$ to $10 / \mathrm{s}$, and strains ranging from 0.05 to 1.2. In Figure 6, good correlation between the predicted and measured flow stresses could be found. The relation factor $\mathrm{R}$ is as high as 0.994 . Therefore, the constitutive equations in this paper are predictive for the high temperature flow behavior of the 3Cr-1Si-1Ni ultra-high strength steel. The constitutive equations have high accuracy and reliability, and can be applied to the field of numerical simulation for the related manufacturing processes such as extrusion [8]. Our thermal-mechanical analysis of the solid state welding processes [32,35] are also successful examples on application of the obtained results in this work. Furthermore, the deviation between the predicted and measured flow stress could be caused by factors, such as the data scatter in 
the experiment and the limitation of the polynomial equations in determining the compensation of strain. High-order polynomials might be used to reduce the deviation.
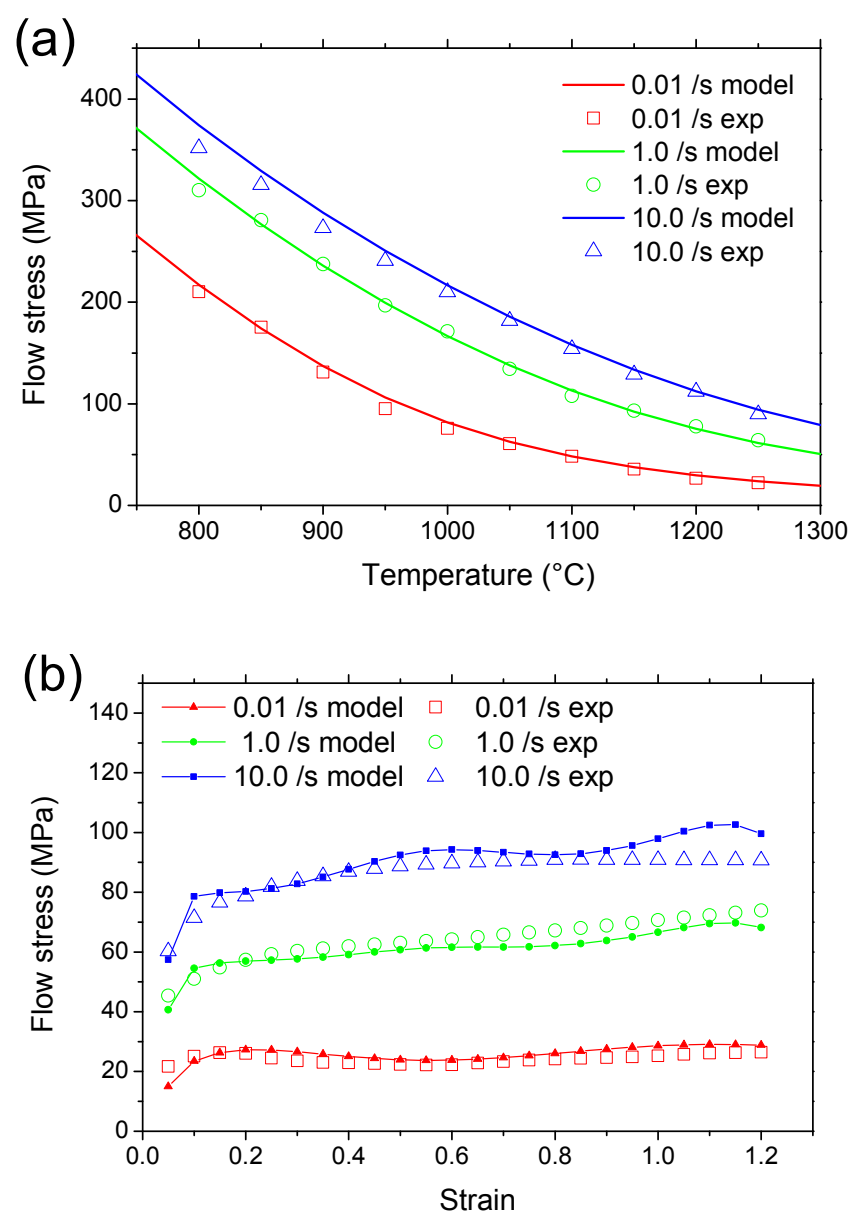

Figure 5. Comparison of measured and predicted flow stresses. (a) Flow stress versus temperature (strain is 0.6); and (b) flow stress versus strain.

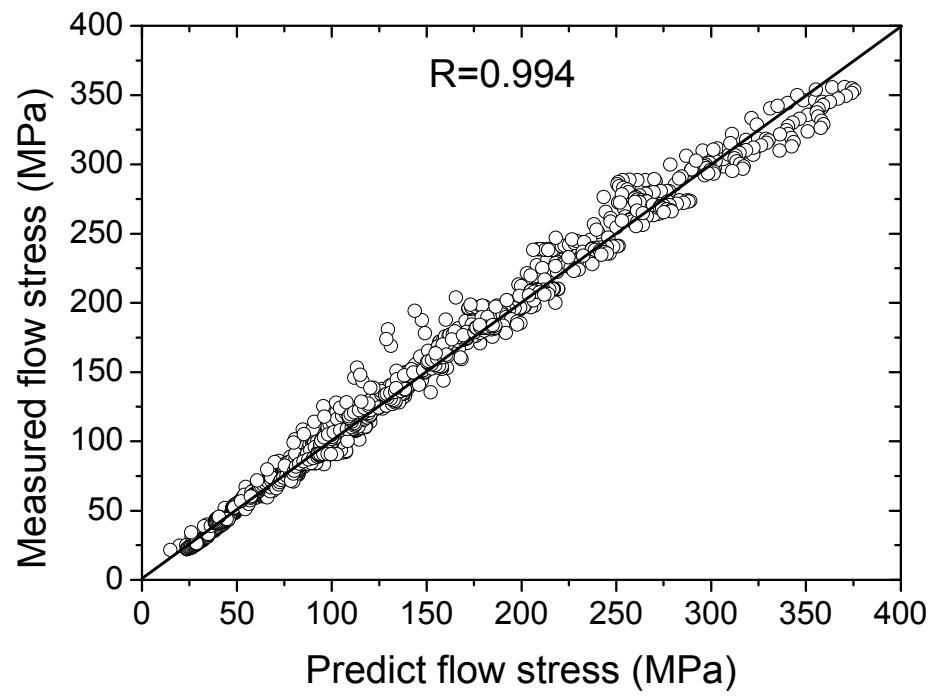

Figure 6. Correlation between the measured and predicted flow stresses. The strain range is $0.05-1.20$ with an interval of 0.05 over all the strain rates $(0.01-10 / \mathrm{s})$ and temperature $\left(800-1250{ }^{\circ} \mathrm{C}\right)$ conditions in the experiments. 


\section{Conclusions}

In this study, we have carried out constitutive analysis on the 3Cr-1Si-1Ni ultra-high strength steel by using experiments and analytical modeling. The conclusions are listed as follows:

(1) The exponent-type constitutive equation, in which the Zener-Hollomon parameter is used to represent the effect of temperature and strain rate on the flow stress. All the material constants are found to be significantly influenced by strain.

(2) The influence of strain in the constitutive model is successfully implemented by introducing strain-dependent constants in the constitutive equations. Fifth-order polynomials are employed to represent the influence of strain on the constitutive constants.

(3) The proposed constitutive equations which consider the compensation of strain is found to accurately predict flow stress. The constitutive equations have high accuracy and reliability, and can be applied to the field of numerical simulation for the related manufacturing processes.

Author Contributions: B.L., G.C., J.P. and Q.S. conceived and designed the experiments; B.L., K.L. and X.W. performed the experiments; B.L. and G.C. analyzed the data; X.W. and X.J., contributed reagents/materials/analysis tools; B.L. wrote the paper.

Funding: This research was funded by National Natural Science Foundation of China, grant number 51705280 and 51375259 and and State Key Laboratory of Tribology, grant number SKLT 2015D07." and "The APC was funded by Tsinghua University.

Conflicts of Interest: The authors declare no conflicts of interest.

\section{References}

1. Lee, H.H.; Yoon, J.I.; Kim, H.S. Single-roll angular-rolling: A new continuous severe plastic deformation process for metal sheets. Scr. Mater. 2018, 146, 204-207. [CrossRef]

2. Yu, J.; Zhao, G.; Chen, L. Analysis of longitudinal weld seam defects and investigation of solid-state bonding criteria in porthole die extrusion process of aluminum alloy profiles. J. Mater. Process. Technol. 2016, 237, 31-47. [CrossRef]

3. Chen, J.; Fujii, H.; Sun, Y.; Morisada, Y.; Kondoh, K. Optimization of mechanical properties of fine-grained non-combustive magnesium alloy joint by asymmetrical double-sided friction stir welding. J. Mater. Process. Technol. 2017, 242, 117-125. [CrossRef]

4. Sellars, C.M.; McTegart, W. On the mechanism of hot deformation. Acta Metall. 1966, 14, 1136-1138. [CrossRef]

5. Shi, L.; Wu, C.S.; Gao, S.; Padhy, G.K. Modified constitutive equation for use in modeling the ultrasonic vibration enhanced friction stir welding process. Scr. Mater. 2016, 119, 21-26. [CrossRef]

6. Tello, K.E.; Gerlich, A.P.; Mendez, P.F. Constants for hot deformation constitutive models for recent experimental data. Sci. Technol. Weld. Join. 2010, 15, 260-266. [CrossRef]

7. McQueen, H.J.; Ryan, N.D. Constitutive analysis in hot working. Mater. Sci. Eng. A 2002, 322, $43-63$. [CrossRef]

8. Chen, L.; Zhao, G.; Yu, J.; Zhang, W. Constitutive analysis of homogenized 7005 aluminum alloy at evaluated temperature for extrusion process. Mater. Des. 2015, 66, 129-136. [CrossRef]

9. Slooff, F.; Zhou, J.; Duszczyk, J.; Katgerman, L. Constitutive analysis of wrought magnesium alloy Mg-Al4-Zn1. Scr. Mater. 2007, 57, 759-762. [CrossRef]

10. Lin, Y.; Chen, M.-S.; Zhong, J. Constitutive modeling for elevated temperature flow behavior of $42 \mathrm{CrMo}$ steel. Comput. Mater. Sci. 2008, 42, 470-477. [CrossRef]

11. Samantaray, D.; Mandal, S.; Bhaduri, A. Constitutive analysis to predict high-temperature flow stress in modified 9Cr-1Mo (P91) steel. Mater. Des. 2010, 31, 981-984. [CrossRef]

12. Shang, X.; He, A.; Wang, Y.; Yang, X.; Zhang, H.; Wang, X. Flow Behavior Modeling of a Nitrogen-Alloyed Ultralow Carbon Stainless Steel During Hot Deformation: A Comparative Study of Constitutive Models. J. Mater. Eng. Perform. 2015, 24, 4106-4118. [CrossRef]

13. Mirzadeh, H.; Cabrera, J.; Prado, J.; Najafizadeh, A. Hot deformation behavior of a medium carbon microalloyed steel. Mater. Sci. Eng. A 2011, 528, 3876-3882. [CrossRef] 
14. Changizian, P.; Zarei-Hanzaki, A.; Roostaei, A.A. The high temperature flow behavior modeling of AZ81 magnesium alloy considering strain effects. Mater. Des. 2012, 39, 384-389. [CrossRef]

15. Cai, Z.; Chen, F.; Guo, J. Constitutive model for elevated temperature flow stress of AZ41M magnesium alloy considering the compensation of strain. J. Alloys Compd. 2015, 648, 215-222. [CrossRef]

16. Ciccarelli, D.; El Mehtedi, M.; Jäger, A.; Spigarelli, S. Analysis of flow stress and deformation mechanism under hot working of ZK60 magnesium alloy by a new strain-dependent constitutive equation. J. Phys. Chem. Solids 2015, 87, 183-195. [CrossRef]

17. Trimble, D.; O'Donnell, G. Constitutive modelling for elevated temperature flow behaviour of AA7075. Mater. Des. 2015, 76, 150-168. [CrossRef]

18. Li, J.-C.; Xie, Z.-Y.; Li, S.-P.; Zang, Y.-Y. Modeling on dynamic recrystallization of aluminium alloy 7050 during hot compression based on cellular automaton. J. Cent. South Univ. 2016, 23, 497-507. [CrossRef]

19. Cai, J.; Li, F.; Liu, T.; Chen, B.; He, M. Constitutive equations for elevated temperature flow stress of Ti-6Al-4V alloy considering the effect of strain. Mater. Des. 2011, 32, 1144-1151. [CrossRef]

20. Peng, X.; Guo, H.; Shi, Z.; Qin, C.; Zhao, Z. Constitutive equations for high temperature flow stress of TC4-DT alloy incorporating strain, strain rate and temperature. Mater. Des. 2013, 50, 198-206. [CrossRef]

21. Xiao, Y.-H.; Guo, C.; Guo, X.-Y. Constitutive modeling of hot deformation behavior of H62 brass. Mater. Sci. Eng. A 2011, 528, 6510-6518. [CrossRef]

22. Wang, Z.; Qi, L.; Zhou, J.; Guan, J.; Liu, J. A constitutive model for predicting flow stress of Al18B4O33w /AZ91D composite during hot compression and its validation. Comput. Mater. Sci. 2011, 50, 2422-2426. [CrossRef]

23. Ahamed, H.; Senthilkumar, V. Hot deformation behavior of mechanically alloyed Al6063/0.75 Al2O3/0.75 Y2O3 nano-composite-A study using constitutive modeling and processing map. Mater. Sci. Eng. A 2012, 539, 349-359. [CrossRef]

24. Zhu, R.; Liu, Q.; Li, J.; Xiang, S.; Chen, Y.; Zhang, X. Dynamic restoration mechanism and physically based constitutive model of 2050 Al-Li alloy during hot compression. J. Alloys Compd. 2015, 650, 75-85. [CrossRef]

25. Zhang, H.; Chen, G.; Chen, Q.; Han, F.; Zhao, Z. A physically-based constitutive modelling of a high strength aluminum alloy at hot working conditions. J. Alloys Compd. 2018, 743, 283-293. [CrossRef]

26. Zener, C.; Hollomon, J.H. Effect of Strain Rate Upon Plastic Flow of Steel. J. Appl. Phys. 1944, 15, $22-32$. [CrossRef]

27. Gao, S.; Wu, C.S.; Padhy, G.K.; Shi, L. Evaluation of local strain distribution in ultrasonic enhanced Al 6061-T6 friction stir weld nugget by EBSD analysis. Mater. Des. 2016, 99, 135-144. [CrossRef]

28. Peng, X.K.; Wuhrer, R.; Heness, G.; Yeung, W.Y. Rolling strain effects on the interlaminar properties of roll bonded copper/aluminium metal laminates. J. Mater. Sci. 2000, 35, 4357-4363. [CrossRef]

29. Arora, A.; Zhang, Z.; De, A.; Debroy, T. Strains and strain rates during friction stir welding. Scr. Mater. 2009, 61, 863-866. [CrossRef]

30. Samantaray, D.; Mandal, S.; Bhaduri, A. A comparative study on Johnson Cook, modified Zerilli-Armstrong and Arrhenius-type constitutive models to predict elevated temperature flow behaviour in modified 9Cr-1Mo steel. Comput. Mater. Sci. 2009, 47, 568-576. [CrossRef]

31. Li, D.; Feng, Y.; Yin, Z.; Shangguan, F.; Wang, K.; Liu, Q.; Hu, F. Hot deformation behavior of an austenitic Fe-20Mn-3Si-3Al transformation induced plasticity steel. Mater. Des. 2012, 34, 713-718. [CrossRef]

32. Chen, G.; Li, H.; Wang, G.; Guo, Z.; Zhang, S.; Dai, Q.; Wang, X.; Zhang, G.; Shi, Q. Effects of pin thread on the in-process material flow behavior during friction stir welding: A computational fluid dynamics study. Int. J. Mach. Tools Manuf. 2018, 124, 12-21. [CrossRef]

33. Buffa, G.; Patrinostro, G.; Fratini, L. Using a neural network for qualitative and quantitative predictions of weld integrity in solid bonding dominated processes. Comput. Struct. 2014, 135, 1-9. [CrossRef]

34. Shi, L.; Wu, C.S.; Sun, Z. An integrated model for analysing the effects of ultrasonic vibration on tool torque and thermal processes in friction stir welding. Sci. Technol. Weld. Join. 2017, 1-15. [CrossRef]

35. Long, L.; Chen, G.; Zhang, S.; Liu, T.; Shi, Q. Finite-element analysis of the tool tilt angle effect on the formation of friction stir welds. J. Manuf. Process. 2017, 30, 562-569. [CrossRef]

(C) 2019 by the authors. Licensee MDPI, Basel, Switzerland. This article is an open access article distributed under the terms and conditions of the Creative Commons Attribution (CC BY) license (http:/ / creativecommons.org/licenses/by/4.0/). 